\title{
Relaxant and vasoprotective effects of ginger extracts on porcine coronary arteries
}

\author{
HSING-CHEN WU ${ }^{1 *}$, CHI-TING HORNG ${ }^{2-4 *}$, SHIH-CHANG TSAI ${ }^{5}$, YOU-LI LEE ${ }^{1}$, SHOU-CHENG HSU ${ }^{4}$, \\ YI-JEN TSAI ${ }^{4}$, FUU-JEN TSAI ${ }^{6,7}$, JO-HUA CHIANG ${ }^{8}$, DAIH-HUANG KUO ${ }^{4}$ and JAI-SING YANG ${ }^{9}$ \\ ${ }^{1}$ Department of Nutrition; ${ }^{2}$ Medical Education Center, Kaohsiung Armed Forces General Hospital, \\ Kaohsiung 80284; ${ }^{3}$ Institute of Biochemistry and Biotechnology, Chung Shang Medical University, Taichung 40201; \\ ${ }^{4}$ Department of Pharmacy and Master Program, Tajen University, Pingtung 90741; ${ }^{5}$ Department of Biological Science \\ and Technology; ${ }^{6}$ School of Post-Baccalaureate Chinese Medicine, China Medical University, Taichung 40402; \\ ${ }^{7}$ Human Genetic Center, China Medical University Hospital, Taichung 40447; ${ }^{8}$ Department of Nursing, Chung-Jen Junior \\ College of Nursing, Health Sciences and Management, Chiayi 62241; ${ }^{9}$ Department of Medical Research, \\ China Medical University Hospital, China Medical University, Taichung 40447, Taiwan, R.O.C.
}

Received June 7, 2016; Accepted November 30, 2017

DOI: $10.3892 /$ ijmm.2018.3380

\begin{abstract}
Ginger (Zingiber officinale Roscoe) is a popular Chinese herbal medicine, which is considered to warm the stomach and dispel cold in traditional Chinese medicine. Ginger is widely used to treat stomach disorders, and it has been reported to exhibit antithrombotic activity via the inhibition of platelet aggregation and thromboxane $\mathrm{B}_{2}$ production in vitro. Cardiovascular disease is associated with the aberrant functioning of the heart and circulatory system; the relatively narrow vessels of the circulation are commonly affected and blocked by atherosclerosis, which may result in angina or heart attack. Numerous drugs and medicines are used to treat myocardial infarction; however, they are often associated with numerous side effects. Therefore, it is important to identify substitutive drugs with no unbearable side effects. In the present study, the relaxant effects of ginger crude extract (GCE) were determined on porcine coronary arteries. The DPPH radical scavenging assay, lucigenin-enhanced chemiluminescence assay and western blot analysis were used to individually detect antioxidant assay of ginger extraction or superoxide anion produced by
\end{abstract}

Correspondence to: Professor Daih-Huang Kuo, Department of Pharmacy and Master Program, Tajen University, 20 Weixin Road, Yanpu, Pingtung 90741, Taiwan, R.O.C.

E-mail:kuo0939@gmail.com

Dr Jai-Sing Yang, Department of Medical Research, China Medical University Hospital, China Medical University, 2 Yuh-Der Road, Taichung 40447, Taiwan, R.O.C.

E-mail: jaisingyang@gmail.com

${ }^{*}$ Contributed equally

Key words: ginger, coronary artery, vasoprotective effect, relaxation, antioxidant endothelial cells and molecular signaling. The results indicated that GCE induced relaxation of porcine coronary arteries in an endothelium-dependent manner. GCE increased vasoprotection via the suppression of nitric oxide synthase and cyclooxygenase. In addition, GCE possessed antioxidant ability, as determined using 1,1-diphenyl-2-picrylhydrazyl and lucigenin-enhanced chemiluminescence assays. Taken together, the present study demonstrated that GCE exerts marked vasoprotective effects and free radical-scavenging activities in porcine coronary arteries.

\section{Introduction}

Cardiovascular disease is the second leading cause of death among the ten leading chronic diseases in Taiwan according to the 2017 annual report of the Ministry of Health and Welfare, Taiwan, R.O.C. (1). A total of 20,812 people died, and the death rate was 88.5 per 100,000 population, increased by $8.1 \%$ from 2015 to 2016 (1). Cardiovascular disease includes coronary heart disease (CHD), peripheral arterial disease, aortic disease and stroke, and many risk factors are associated with the lesions $(2,3)$. The drug treatments can greatly improve cardiovascular disease (4). Importantly, traditional Chinese medicine, dietary foods and supplements may prevent or help in fighting heart disease $(5,6)$.

Ginger (Zingiber officinale Roscoe) is a natural herb that is widely used for medicinal and culinary purposes $(7,8)$. Ginger exerts many health benefits and may be used to treat ailments, including cramps, arthritis and disorders of the gastrointestinal tract, such as constipation, dyspepsia, diarrhea, nausea and vomiting (8). In addition, ginger is recommended by traditional healers to treat cardiomyopathy, high blood pressure and palpitations $(7,9,10)$. The main bioactive constituents of ginger are gingerol, shogaol, zingerone and paradol $(11,12)$. Furthermore, the main aromatic components of ginger are zingiberol, gingediol, monoacyldigalactosyl-glycerol, iarylheptanoids and phytosterols (13). 6-Gingerol has numerous biological activi- 
ties, including antioxidant, antitumor and anti-inflammatory effects (14-16). The pharmacological effects of 6-gingerol ameliorate hyperlipidemia by decreasing serum cholesterol and serum triglyceride levels (17). 6-shogaol is a dehydrated form of 6-gingerol, which is isolated from the dried or cooked rhizomes of ginger $(18,19)$. In a previous study, ginger crude extract (GCE) was reported to exhibit hypotensive, endothelium-independent vasodilatory and cardiosuppressive properties, via its specific inhibitory action at voltage-dependent calcium channels (20). The present study aimed to investigate the relaxant effects of GCE on porcine coronary arteries in vivo.

\section{Materials and methods}

Reagents and chemicals. DL-homocysteine (Hcy), 1H-[1,2,4] oxadiazolo[4,3-a]quinoxalin-1-one (ODQ), bradykinin, 1,1-diphenyl-2-picrylhydrazyl (DPPH), dimethyl sulfoxide, propranolol, $n$-butanol and other chemicals were high-grade products purchased from Sigma-Aldrich (Merck KGaA, Darmstadt, Germany). $N^{\mathrm{G}}$-nitro- ${ }_{\mathrm{L}}$-arginine $\left({ }_{\mathrm{L}}-\mathrm{NNA}\right)$ and glibenclamide (Glib) were obtained from MP Biomedicals, LLC (Santa Ana, CA, USA). KH solution was composed of $70.2 \mathrm{mM} \mathrm{NaCl}, 4.2 \mathrm{mM} \mathrm{KCl}, 2.8 \mathrm{mM} \mathrm{CaCl}_{2}, 2.7 \mathrm{mM} \mathrm{MgSO}_{4}$,

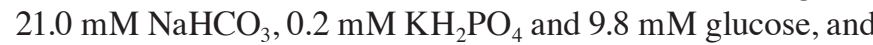
the $\mathrm{pH}$ was adjusted to 7.4 .

Ginger extraction. A total of $600 \mathrm{~g}$ fresh ginger rhizome was soaked in 2.51 ethanol. The extracts were refluxed at $78^{\circ} \mathrm{C}$ for $2 \mathrm{~h}$; this was repeated three times. Subsequently, the filtrate was concentrated in a rotary evaporator. The weight of extracts was $\sim 34.2 \mathrm{~g}$ (yield, 5.7\%). The residue was then suspended in $50 \mathrm{ml}$ water and extracted with $50 \mathrm{ml}$ chloroform twice, after which the chloroform partition was evaporated to obtain $8.4 \mathrm{~g}$ residue (GCE). The aqueous phase was partitioned with $n$-butanol. The $n$-butanol partition was evaporated to obtain $6.3 \mathrm{~g}$ residue (ginger $n$-butanol extract, GNE). The water extract underwent reverse osmosis to obtain $19.5 \mathrm{~g}$ residue (ginger water extract, GWE); this process is summarized in Fig. 1. The stock solution of ginger extraction was prepared by dimethyl sulfoxide to dilute for further experiments.

Coronary artery ring preparation. Porcine hearts were freshly obtained from the local abattoir, immersed in cold $0.9 \% \mathrm{NaCl}$ at $4^{\circ} \mathrm{C}$ and were transported to the research laboratory. Excess connective tissue was removed and the arteries were cut into 5-mm rings. Endothelium-intact and -denuded porcine coronary artery rings were prepared, and the rings were then mounted with two stainless steel hooks in $10 \mathrm{ml} \mathrm{KH}$ solution-filled organ baths. $\mathrm{KH}$ solution was kept in oxygenated conditions $\left(95 \% \mathrm{O}_{2}\right.$ and $\left.5 \% \mathrm{CO}_{2}\right)$ at $37^{\circ} \mathrm{C}$ and was replaced every $15 \mathrm{~min}$ to maintain continuous equilibration. The rings were perfused with $30 \mathrm{mM} \mathrm{KCl}$ in the organ bath until tonic phase contraction was achieved, as previously described (21) before pretreatment with $100 \mu \mathrm{M}$ L-NNA, $10 \mu \mathrm{M}$ ODQ, $10 \mu \mathrm{g} /$ $\mathrm{ml}$ indomethacin, $20 \mu \mathrm{M}$ propranolol, $1 \mu \mathrm{M}$ Glib, $100 \mu \mathrm{M}$ Hcy, $30 \mathrm{mM}$ bradykinin and $77.5 \mathrm{mM} \mathrm{H}_{2} \mathrm{O}_{2}$, respectively, for indicated period of time.

Isometric tension of porcine coronary arteries. The porcine coronary arteries were harvested, cut into numerous 5-mm

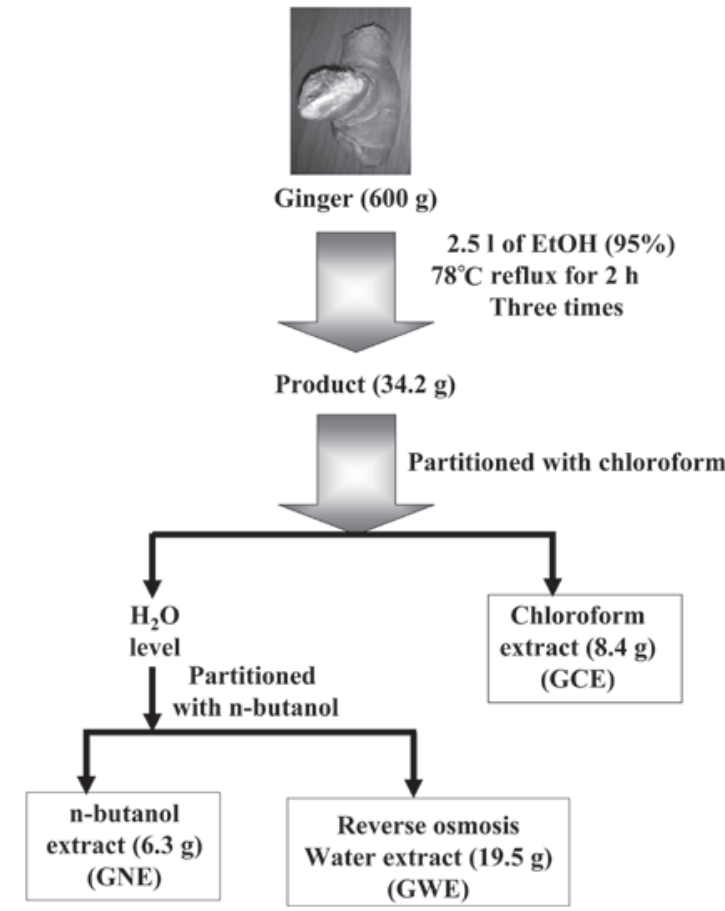

Figure 1. Flowchart depicting the preparation of three varieties of ginger extract (GCE, GNE and GWE). GCE, ginger crude extract; GNE, ginger $n$-butanol extract; GWE, ginger water extract.

rings, and were maintained in $5 \mathrm{ml}$ organ baths containing $95 \% \mathrm{O}_{2}$ and $5 \% \mathrm{CO}_{2}$ at $37^{\circ} \mathrm{C}$. Ginger extracts were individually added to the $5-\mathrm{mm}$ rings for $30 \mathrm{~min}$ and relaxation was observed. Alterations in tension were recorded using a Grass Force displacement transducer (model FT03; Grass; Natus Medical Incorporated, Pleasanton, CA, USA).

DPPH radical scavenging assay. The DPPH radical scavenging assay was performed according to the method described by Sakanashi et al (21). Briefly, in each well of a 96-well plate, $50 \mu \mathrm{l}$ sample extract was added to $150 \mu 10.25 \mathrm{mM}$ DPPH methanolic solution. After mixing thoroughly, the reactants were incubated in the dark for $30 \mathrm{~min}$ at room temperature. The control was prepared by mixing $50 \mu 1$ methanol with $150 \mu 1$ DPPH. The absorbance was detected at $517 \mathrm{~nm}$ using a spectrophotometer. Samples were measured in triplicate.

Lucigenin-enhanced chemiluminescence assay. The levels of superoxide anion produced by endothelial cells of the porcine arteries were detected using the lucigenin-enhanced chemiluminescence method, as previously described by Sun et al (22). Briefly, the samples of GCE, GNE and GWE were mixed with $5 \mu \mathrm{M}$ lucigenin for $6 \mathrm{~min}$. Time-based reading was recorded in a 5 min period using a luminometer. The area of each vessel segment was measured using a caliper and was used to normalize the data for each sample.

Protein preparation. Following treatment with or without GCE, GWE and GNE, porcine coronary artery endothelial cells were collected as previously described (23) and mixed with protein lysis buffer [50 mM Tris- $\mathrm{HCl}$ (pH 7.4), $1 \mathrm{mM} \mathrm{NaF}$, $150 \mathrm{mM} \mathrm{NaCl}, 1 \mathrm{mM}$ EGTA, $1 \mathrm{mM}$ phenylmethane-sulfonyl fluoride, $1 \% \mathrm{NP}-40$ and $10 \mu \mathrm{g} / \mathrm{ml}$ leupeptin] on ice. The samples 
were homogenized for $20 \mathrm{sec}$, incubated for $20 \mathrm{~min}$ on ice and centrifuged at $15,000 \mathrm{x} \mathrm{g}$ for $30 \mathrm{~min}$ at room temperature. The supernatants were then transferred into new tubes for protein quantification, as previously described $(24,25)$.

Western blot analysis. A total of $50 \mu \mathrm{g}$ protein was loaded and separated by $10 \%$ SDS-PAGE. The samples in the gels were then transferred onto polyvinylidene difluoride membranes. The membranes were incubated with $0.1 \%$ PBS-Tween containing 5\% non-fat milk for $30 \mathrm{~min}$ at room temperature, and were then hybridized with cyclooxygenase-2 (COX-2; cat.no.GTX100656; 1:1,000dilution;GenTex,Hsinchu,Taiwan), inducible nitric oxide synthase (iNOS; cat. no. GTX130246; 1:1,000 dilution; GenTex), endothelial nitric oxide synthase (eNOS; cat. no. 3GTX129843; 1:1,000 dilution; GenTex) and $\beta$-actin (cat. no. GTX109639; 1:5,000 dilution; GenTex) primary antibodies. Subsequently, membranes were incubated with horseradish peroxidase-conjugated rabbit $\mathrm{IgG}$ antibody (cat. no. GTX213110-01; 1:10,000 dilution; GenTex) at room temperature for $1 \mathrm{~h}$ and were then visualized using Immobilon Western HRP substrate kit (EMD Millipore, Billerica, MA, USA). Densitometric analysis of each band was performed utilizing National Institutes of Health (NIH) ImageJ 1.47 software (NIH, Bethesda, MD, USA).

Statistical analysis. Data are presented as the means \pm standard deviation from at least three separate experiments. Statistical data were analyzed using one-way ANOVA with post hoc Dunnett's test for comparing groups to the control by SPSS version 13.0 for Windows (SPSS Inc., Chicago, IL, USA). $\mathrm{P}<0.05$ was considered to indicate a statistically significantly difference.

\section{Results}

Ginger extracts (GCE, GNE and GWE) preparation. The three varieties of ginger extract (GCE, GNE and GWE) were prepared according to the diagram presented in Fig. 1. These three ginger extracts were used in the present study to explore their effects on the vasorelaxation of porcine coronary artery rings.

GCE relaxes porcine coronary arteries. Porcine coronary arteries were suspended in an organ bath. Various amounts of $\operatorname{GCE}(1,3,10,30$ and $100 \mu \mathrm{g} / \mathrm{ml})$ were added to the porcine coronary arteries; water was used as a vehicle control. A dose-dependent increase in relaxation was observed in response to GCE (Fig. 2).

GCE induces endothelium-dependent relaxation of porcine coronary arteries. The results of the present study indicated that GCE induced endothelium-dependent vasorelaxation. Endothelium-intact and -denuded porcine coronary artery rings were incubated with various amounts of $\operatorname{GCE}(1,3,10$, 30 and $100 \mu \mathrm{g} / \mathrm{ml}$ ). GCE was able to reduce $\mathrm{KCl}$-induced contraction and increase vasorelaxation from 27 to $99 \%$ in the endothelium-intact porcine coronary artery rings, whereas GCE exerted mild effects on the vasorelaxation of denuded porcine coronary artery rings (from 15 to 93\%) (Fig. 3). Based on these data, it was suggested that endothelium-dependent

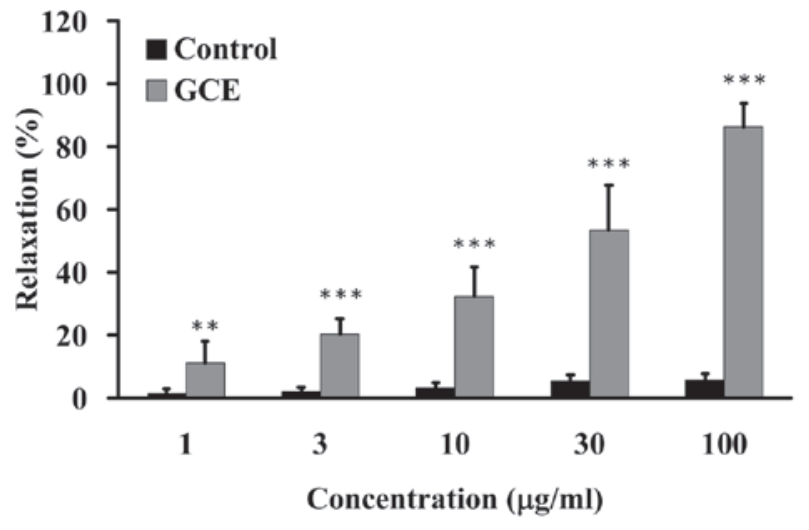

Figure 2. Vasodilatory effects of GCE on KCl-induced contraction Various amounts of GCE were added to the porcine coronary arteries and $\mathrm{KCl}$-induced contractions were evaluated. Data are presented as a percentage of $30 \mathrm{mM} \mathrm{KCl}$-induced contraction based on tension changes. Values are expressed as the means \pm standard deviation $(\mathrm{n}=6) .{ }^{* * *} \mathrm{P}<0.01$ and ${ }^{* * *} \mathrm{P}<0.001$ vs. the control group. GCE, ginger crude extract.

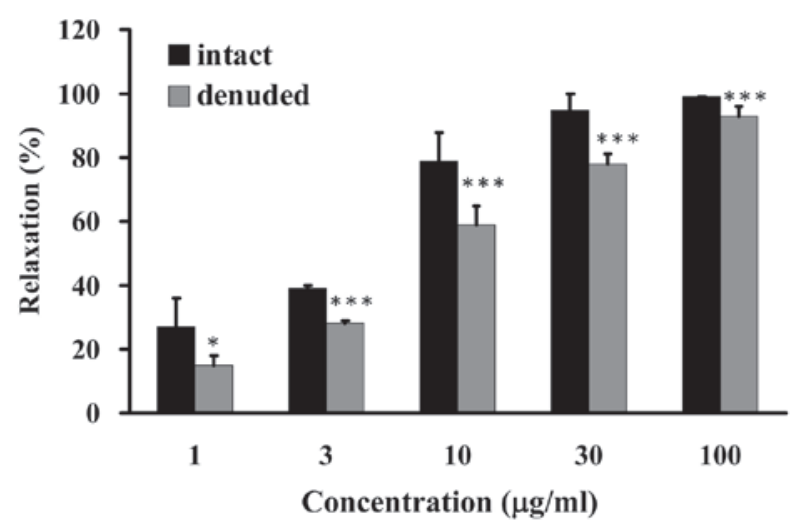

Figure 3. Effects of GCE on endothelium-dependent vasorelaxation Endothelium-intact and -denuded porcine coronary artery rings were incubated with various amounts of $\operatorname{GCE}(1,3,10,30$ and $100 \mu \mathrm{g} / \mathrm{ml})$. Tension was determined by isometric force transduction. Data are presented as a percentage of $30 \mathrm{mM} \mathrm{KCl}$-induced contraction. Values are expressed as the means \pm standard deviation $(n=6) .{ }^{*} \mathrm{P}<0.05$ and ${ }^{* * *} \mathrm{P}<0.001$ vs. the intact group. GCE, ginger crude extract.

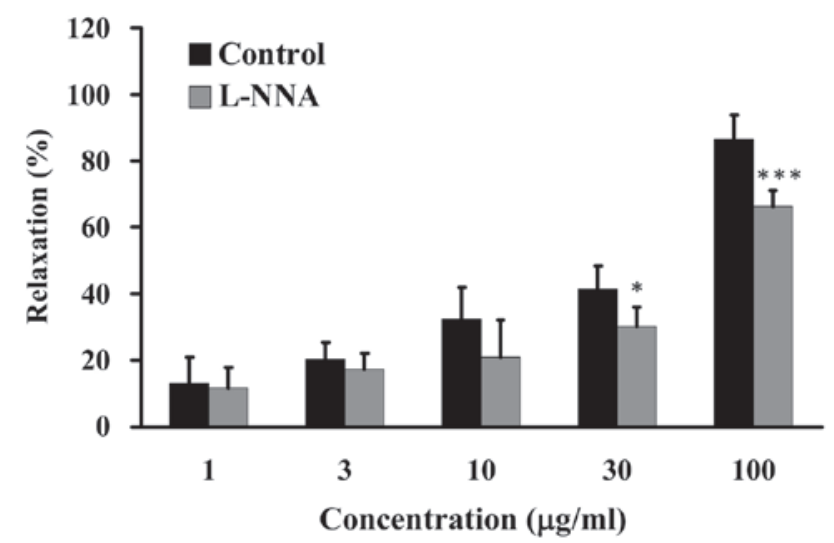

Figure 4. Effects of ${ }_{\mathrm{L}}$-NNA on GCE-induced vasorelaxation. Porcine coronary artery rings were incubated with various amounts of $\operatorname{GCE}(1,3,10$, 30 and $100 \mu \mathrm{g} / \mathrm{ml}$ ) in the absence (control) or presence of ${ }_{\mathrm{L}}$-NNA. Tension was determined by isometric force transduction. Data are presented as a percentage of $30 \mathrm{mM} \mathrm{KCl}$-induced contraction. Values are expressed as the means \pm standard deviation $(n=6) .{ }^{* * * *} \mathrm{P}<0.001$ vs. the control group. ${ }_{\mathrm{L}}-\mathrm{NNA}$, $N^{\mathrm{G}}$-nitro-$-\mathrm{L}$-arginine; GCE, ginger crude extract. 


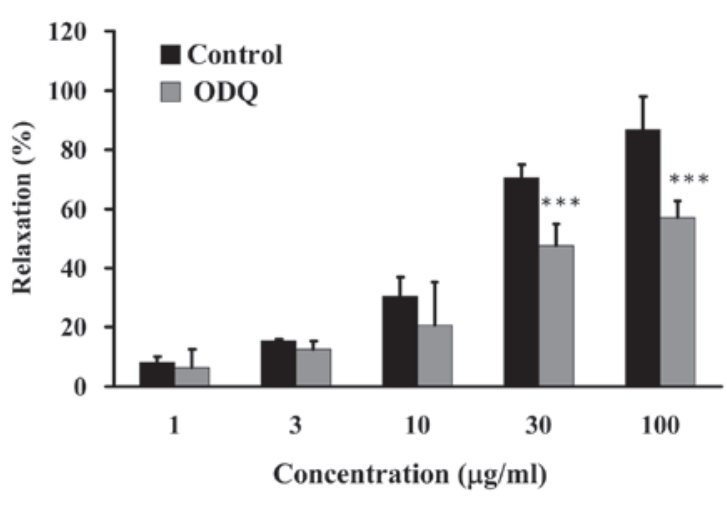

Figure 5. Effects of ODQ on GCE-induced vasorelaxation. Porcine coronary artery rings were incubated with various amounts of $\operatorname{GCE}(1,3,10$, 30 and $100 \mu \mathrm{g} / \mathrm{ml}$ ) in the absence (control) or presence of ODQ. Tension was determined by isometric force transduction. Data are presented as a percentage of $30 \mathrm{mM} \mathrm{KCl}$-induced contraction. Values are expressed as the means \pm standard deviation $(n=6) .{ }^{* * * *} \mathrm{P}<0.001$ vs. the control group. GCE, ginger crude extract; ODQ, $1 \mathrm{H}$-[1,2,4] oxadiazolo[4,3-a]quinoxalin-1-one.

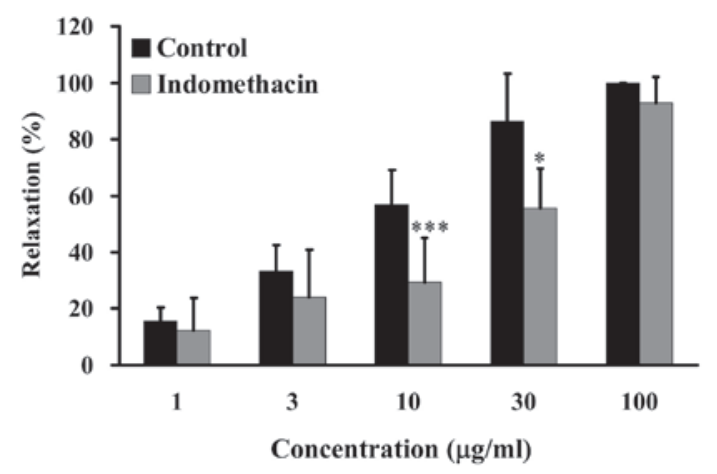

Figure 6. Effects of indomethacin on GCE-induced vasorelaxation Porcine coronary artery rings were incubated with various amounts of GCE $(1,3$, 10,30 and $100 \mu \mathrm{g} / \mathrm{ml}$ ) in the absence (control) or presence of indomethacin. Tension was determined by isometric force transduction. Data are presented as a percentage of $30 \mathrm{mM} \mathrm{KCl}$-induced contraction. Values are expressed as the means \pm standard deviation $(\mathrm{n}=6) .{ }^{*} \mathrm{P}<0.05$ and ${ }^{* * * *} \mathrm{P}<0.001$ vs. the control group. GCE, ginger crude extract.

relaxation was increased in porcine coronary arteries following GCE exposure.

The NOS signaling pathway is involved in GCE-induced relaxation. Numerous in vitro and in vivo studies have reported that endothelium-dependent relaxation and vasodilatation persist in the presence of NOS inhibitors, including L-arginine analogues, such as ${ }_{\text {LNNA }}(23,26)$. Porcine coronary artery rings were pretreated in the absence (control) or presence of $100 \mu \mathrm{M}_{\mathrm{L}}$-NNA for $20 \mathrm{~min}$, and were then incubated with $30 \mathrm{mM} \mathrm{KCl}$ to induce contraction until the tonic phase (27). Relaxation was examined in the presence of various concentrations of GCE $(1,3,10,30$ and $100 \mu \mathrm{g} / \mathrm{ml})$ in an organ bath. GCE induced relaxation of porcine coronary artery rings from 13 to $86 \%$ without ${ }_{\mathrm{L}}$-NNA pretreatment. Conversely, GCE $(100 \mu \mathrm{g} / \mathrm{ml})$ induced relaxation of porcine coronary artery rings to $66 \%$, in the presence of ${ }_{\mathrm{L}}$-NNA (Fig. 4). These results revealed that GCE-induced relaxation of porcine coronary arteries may be mediated by the NOS signaling pathway.

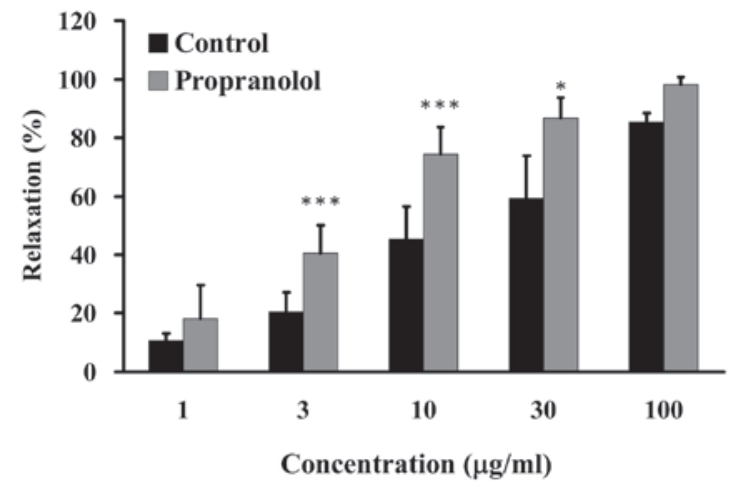

Figure 7. Effects of propranolol on GCE-induced vasorelaxation. Porcine coronary artery rings were incubated with various amounts of GCE $(1,3$, 10,30 and $100 \mu \mathrm{g} / \mathrm{ml}$ ) in the absence (control) or presence of propranolol. Tension was determined by isometric force transduction. Data are presented as a percentage of $30 \mathrm{mM} \mathrm{KCl}$-induced contraction. Values are expressed as the means \pm standard deviation $(n=6)$. ${ }^{*} \mathrm{P}<0.05$ and ${ }^{* * *} \mathrm{P}<0.001$ vs. the control group. GCE, ginger crude extract.

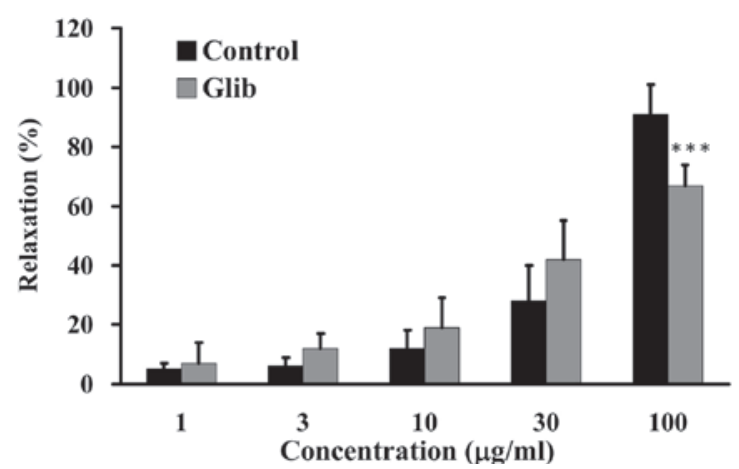

Figure 8. Effects of Glib on GCE-induced vasorelaxation. Porcine coronary artery rings were incubated with various amounts of $\operatorname{GCE}(1,3,10$, 30 and $100 \mu \mathrm{g} / \mathrm{ml}$ ) in the absence (control) or presence of Glib. Tension was determined by isometric force transduction. Data are presented as a percentage of $30 \mathrm{mM} \mathrm{KCl}$-induced contraction. Values are expressed as the means \pm standard deviation $(n=6) .{ }^{* * * *} \mathrm{P}<0.001$ vs. the control group. GCE, ginger crude extract; Glib, glibenclamide.

GCE improves relaxation via NO-activated soluble guanylate cyclase $(s G C)$. The present study determined the effects of GCE on sGC-induced relaxation. Porcine coronary artery rings were pretreated in the absence (control) or presence of $10 \mu \mathrm{M}$ ODQ for $20 \mathrm{~min}$, and were then incubated with $30 \mathrm{mM} \mathrm{KCl}$ to induce contraction until the tonic phase. Relaxation was examined in the presence of various concentrations of $\operatorname{GCE}(1,3,10,30$ and $100 \mu \mathrm{g} / \mathrm{ml})$ in an organ bath. GCE induced an increase in relaxation from 8 to $87 \%$ in porcine coronary artery rings following pretreatment without $10 \mu \mathrm{M}$ ODQ. Conversely, relaxation of porcine coronary artery rings was significantly reduced following pretreatment with $10 \mu \mathrm{M}$ ODQ and treatment with GCE at 30 and $100 \mu \mathrm{g} / \mathrm{ml}$ (Fig. 5). These results indicated that NO is a vital factor in GCE-induced relaxation of porcine coronary arteries.

GCE improves relaxation via COX. The present study further examined the effects of GCE on relaxation following treatment with indomethacin, which is an inhibitor of COX. Porcine 
coronary artery rings were pretreated in the absence (control) or presence of $1 \mu \mathrm{g} / \mathrm{ml}$ indomethacin for $20 \mathrm{~min}$, and were then incubated with $30 \mathrm{mM} \mathrm{KCl}$ to induce contraction until the tonic phase. Relaxation was examined in the presence of various concentrations of $\operatorname{GCE}(1,3,10,30$ and $100 \mu \mathrm{g} / \mathrm{ml})$ in an organ bath. GCE induced an increase in relaxation from 15 to $100 \%$ in porcine coronary artery rings without $1 \mu \mathrm{g} / \mathrm{ml}$ indomethacin treatment. Conversely, following pretreatment with $1 \mu \mathrm{g} / \mathrm{ml}$ indomethacin and treatment with low concentrations of GCE (3-30 $\mu \mathrm{g} / \mathrm{ml})$, relaxation of porcine coronary artery rings was significantly attenuated (Fig. 6). These results suggested that GCE attenuated relaxation induced by arachidonic acid. GCE-induced relaxation of porcine coronary arteries may be through COX pathway.

GCE has no effect on relaxation induced by $\beta 1$-adrenergic receptor blocker. $\beta$-blockers have been widely used in the treatment of numerous cardiovascular diseases, particularly hypertension and atherosclerosis (28). Some $\beta 1$-adrenergic receptor blockers cause vasodilation by increasing NO (29). The present study examined the effects of GCE on relaxation induced by propranolol, which is a $\beta$-blocker. Porcine coronary artery rings were pretreated in the absence (control) or presence of $20 \mu \mathrm{M}$ propranolol for $20 \mathrm{~min}$, and were then incubated with $30 \mathrm{mM} \mathrm{KCl}$ to induce contraction until the tonic phase. Relaxation was examined in the presence of various amounts of $\operatorname{GCE}(1,3,10,30$ and $100 \mu \mathrm{g} / \mathrm{ml})$ in an organ bath. GCE at $3-30 \mu \mathrm{g} / \mathrm{ml}$ induced an increase in relaxation from 11 to $91 \%$ in porcine coronary artery rings without pretreatment with $20 \mu \mathrm{M}$ propranolol (Fig. 7). These results indicated that GCE exhibited no apparent effect on propranolol-induced relaxation.

ATP-sensitive potassium $\left(K_{\mathrm{ATP}}\right)$ channel blocker exerts no effects on GCE-induced relaxation. $\mathrm{K}_{\text {ATP }}$ channels are activated and opened by declining intracellular ATP levels and elevated cAMP concentration, which leads to hyperpolarization of endothelial cells and the promotion of NO formation in vitro $(30,31)$. It has been suggested that endothelial cell hyperpolarization may contribute to vascular relaxation. $\mathrm{K}_{\text {ATP }}$ channels are inhibited by sulfonylurea agents, including Glib $(31,32)$. The present study examined the effects of Glib, a $\mathrm{K}_{\text {АтP }}$ channel blocker, on GCE-induced relaxation. Porcine coronary artery rings were pretreated in the absence (control) or presence of $1 \mu \mathrm{M}$ Glib for $60 \mathrm{~min}$, and were then incubated with $30 \mathrm{mM} \mathrm{KCl}$ to induce contraction until the tonic phase. Relaxation was examined in the presence of various amounts of $\operatorname{GCE}(1,3,10,30$ and $100 \mu \mathrm{g} / \mathrm{ml})$ in an organ bath. GCE induced an increase in relaxation from 15 to $76 \%$ in the porcine coronary artery rings without $1 \mu \mathrm{M}$ Glib pretreatment (Fig. 8). These results suggested that Glib had no effect on GCE-induced relaxation.

GCE prevents Hcy-induced endothelial vasomotor dysfunction. The present study investigated the effects of GCE on Hcy-induced endothelial cell damage. Porcine coronary artery rings were incubated with $30 \mu \mathrm{g} / \mathrm{ml} \mathrm{GCE}$ for $15 \mathrm{~min}$, and were then treated with $100 \mu \mathrm{M}$ Hcy for $30 \mathrm{~min}$. Porcine coronary artery rings were placed in an organ bath containing $30 \mathrm{mM}$ $\mathrm{KCl}$ to induce contraction until the tonic phase. Relaxation was

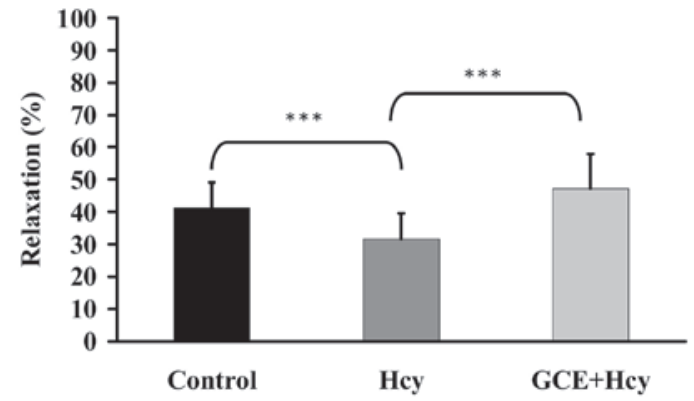

Figure 9. GCE improves Hcy-induced endothelial vasomotor dysfunction. Porcine coronary artery rings were incubated in the absence (control) or presence of $30 \mu \mathrm{g} / \mathrm{ml} \mathrm{GCE}$ for $15 \mathrm{~min}$, and were then treated with $100 \mu \mathrm{M}$ Hcy for $30 \mathrm{~min}$. Data are presented as a percentage of $30 \mathrm{mM} \mathrm{KCl-induced}$ contraction. Values are expressed as the means \pm standard deviation $(n=6)$.

${ }^{* * * *} \mathrm{P}<0.001$. GCE, ginger crude extract; Hcy, homocysteine.

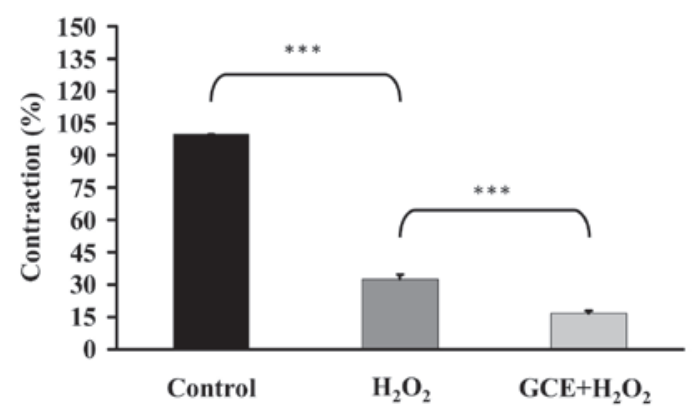

Figure 10. GCE improves $\mathrm{H}_{2} \mathrm{O}_{2}$-induced endothelial vasomotor dysfunction. Porcine coronary artery rings were incubated in the absence (control) or presence of $30 \mu \mathrm{g} / \mathrm{ml} \mathrm{GCE}$ for $15 \mathrm{~min}$ and were then treated with $77.5 \mathrm{mM}$ $\mathrm{H}_{2} \mathrm{O}_{2}$ for $30 \mathrm{~min}$. Data are presented as a percentage of $30 \mathrm{mM} \mathrm{KCl}$-induced contraction. ${ }^{* * *} \mathrm{P}<0.001$. GCE, ginger crude extract; $\mathrm{H}_{2} \mathrm{O}_{2}$, hydrogen peroxide.

examined following the addition of $30 \mathrm{mM}$ bradykinin into the organ bath. Hcy reduced relaxation, whereas GCE significantly prevented Hcy-induced endothelial dysfunction (Fig. 9). These results indicated that GCE may improve Hcy-induced endothelial cell damage.

GCE prevents hydrogen peroxide $\left(\mathrm{H}_{2} \mathrm{O}_{2}\right)$-induced endothelial cell damage. The present study clarified the effects of GCE on $\mathrm{H}_{2} \mathrm{O}_{2}$-induced endothelial cell damage. Porcine coronary artery rings were incubated with $30 \mu \mathrm{g} / \mathrm{ml} \mathrm{GCE}$ for $15 \mathrm{~min}$, and were then placed in an organ bath containing $30 \mathrm{mM} \mathrm{KCl}$ to induce contraction until the tonic phase. Rings were treated with $77.5 \mathrm{mM} \mathrm{H}_{2} \mathrm{O}_{2}$ for 15 min and contraction was examined. $\mathrm{H}_{2} \mathrm{O}_{2}$ induced endothelial contraction, whereas GCE significantly prevented $\mathrm{H}_{2} \mathrm{O}_{2}$-induced endothelial dysfunction (Fig. 10). These data revealed that GCE may attenuate $\mathrm{H}_{2} \mathrm{O}_{2}$-induced endothelial cell injury.

Ginger extracts possess antioxidant abilities. Reactive oxygen species (ROS) are produced under oxidative stress and adverse cellular environments (33). Vitamins $\mathrm{E}$ and $\mathrm{C}, \beta$-carotene, flavonoids and polyphenols have previously been demonstrated to possess free radical-scavenging abilities (34). In the present study, the antioxidant properties of ginger extracts were individually determined according to DPPH and lucigenin-enhanced chemiluminescence assays. DPPH absorbance decreased 
A
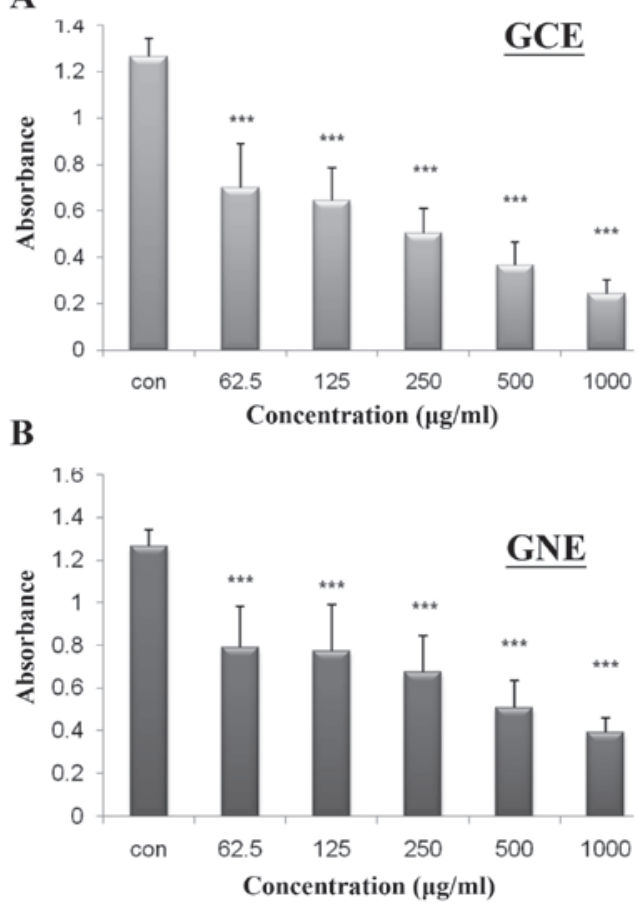

C

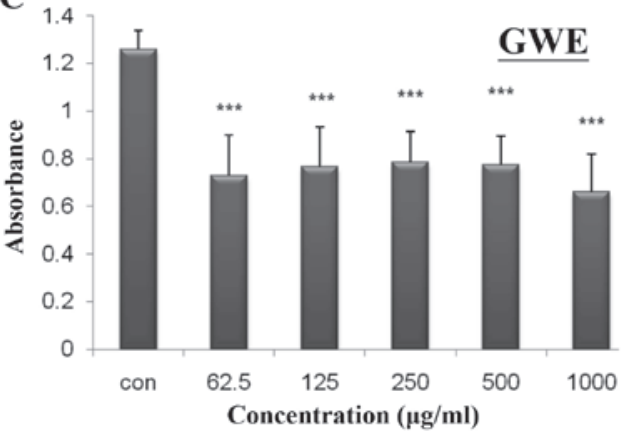

Figure 11. DPPH-scavenging activities of three varieties of ginger extract DPPH was mixed with various amounts $(62.5,125,250,500$ and $1,000 \mu \mathrm{g} / \mathrm{ml})$ of (A) GCE, (B) GNE and (C) GWE. Data are presented as absorbance read at $517 \mathrm{~nm}$. Values are expressed as the means \pm standard deviation. ${ }^{* * *} \mathrm{P}<0.001$ vs. the control group $(n=6)$. DPPH, 1,1-diphenyl-2-picrylhydrazyl; GCE, ginger crude extract; GNE, ginger $n$-butanol extract; GWE, ginger water extract.

from 0.70 to 0.24 , as GCE concentration increased from 62.5 to $1,000 \mu \mathrm{g} / \mathrm{ml}$ (Fig. 11A). The rate of inhibition was increased from 40 to $85 \%$ in a dose-dependent manner. DPPH absorbance decreased from 0.79 to 0.39 , as GNE concentration increased from 62.5 to $1,000 \mu \mathrm{g} / \mathrm{ml}$. The rate of inhibition was increased from 37 to $78 \%$ in a dose-dependent manner (Fig. 11B). DPPH absorbance decreased from 0.73 to 0.66 , as GWE concentration increased from 62.5 to $1,000 \mu \mathrm{g} / \mathrm{ml}$. The rate of inhibition was increased from 42 to $48 \%$ (Fig. 11C). These findings indicated that GCE possesses a stronger ability to reduce free radical levels. To determine whether ginger extracts possess $\mathrm{H}_{2} \mathrm{O}_{2}$-scavenging abilities, a lucigenin-enhanced chemiluminescence assay was conducted. Various concentrations of GCE, GNE and GWE were used to evaluate their ability to remove $\mathrm{H}_{2} \mathrm{O}_{2}$. The $\mathrm{H}_{2} \mathrm{O}_{2}$-scavenging ability was increased from 10 to $52 \%$ in response to GCE (Fig. 12A). The $\mathrm{H}_{2} \mathrm{O}_{2}$-scavenging ability was increased from 68 to $94 \%$ in response to GNE (Fig. 12B) and from 63 to $90 \%$ in response
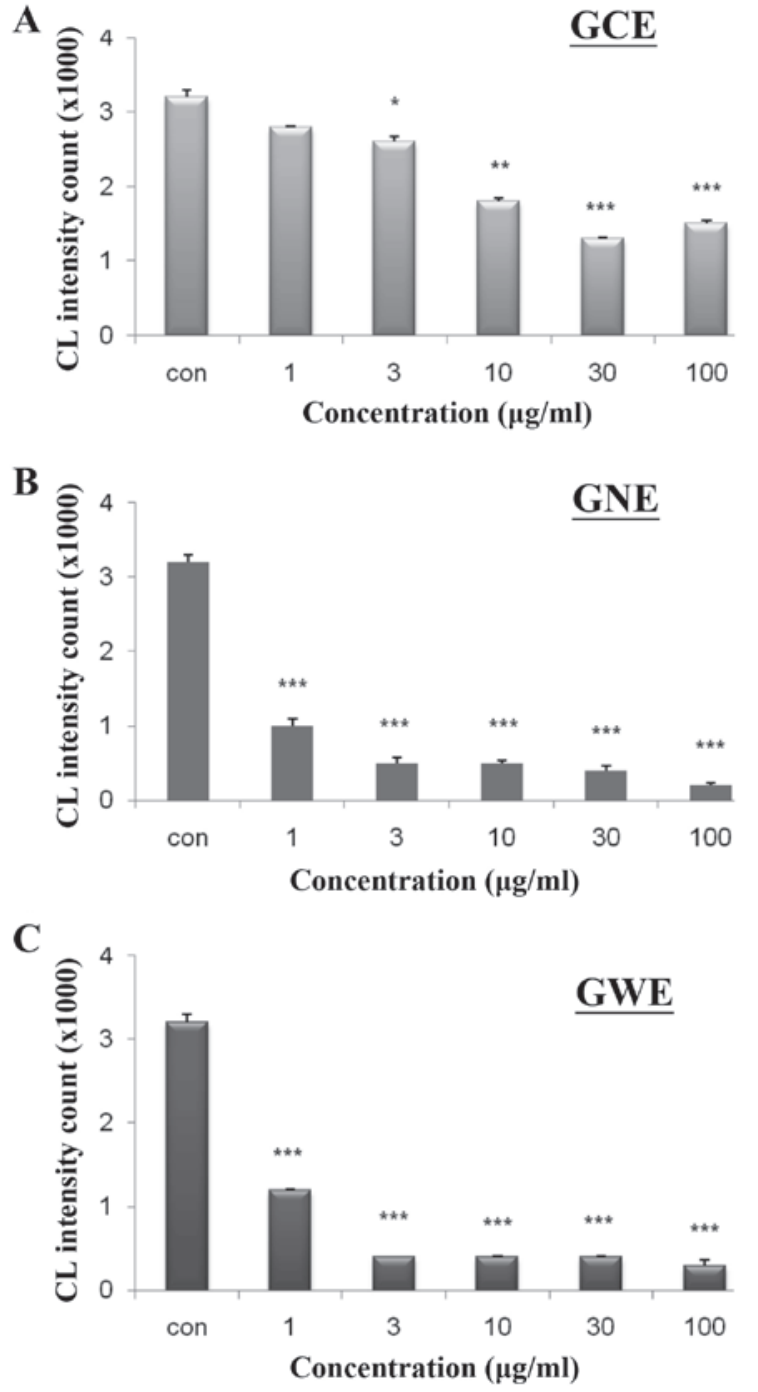

Figure 12. Antioxidant activities of three varieties of ginger extract were evaluated by lucigenin-enhanced chemiluminescence assay. Lucigenin was mixed with various amounts $(1,3,10,30$ and $100 \mu \mathrm{g} / \mathrm{ml})$ of (A) GCE, (B) GNE and (C) GWE. Data are presented as absorbance read at $517 \mathrm{~nm}$. Values are expressed as the means \pm standard deviation $(n=6)$. ${ }^{*} \mathrm{P}<0.05,{ }^{* *} \mathrm{P}<0.01$ and ${ }^{* * *} \mathrm{P}<0.001$ vs. the control group. GCE, ginger crude extract; GNE, ginger $n$-butanol extract; GWE, ginger water extract; CL, chemiluminescence.

to GWE (Fig. 12C). These findings indicated that GCE may possess a stronger antioxidant ability to scavenge free radicals.

GCE exerts strong vasoprotective effects. The present study investigated the effects of ginger extracts on Hcy-induced endothelial cell damage by analyzing the protein expression levels of endothelial NOS (eNOS), iNOS and COX-2. Hcy increased eNOS, iNOS and COX-2 expression. In the absence of Hcy, GWE induced eNOS, maintained iNOS and reduced COX-2 expression (Fig. 13A). Conversely, low concentration $(10 \mu \mathrm{g} / \mathrm{ml})$ of GWE slightly reduced eNOS, slightly induced iNOS and reduced COX-2 expression in the presence of Hcy. A high concentration $(30 \mu \mathrm{g} / \mathrm{ml})$ of GWE markedly reduced the expression levels of eNOS, iNOS and COX-2 in the presence of Hcy. GCE markedly reduced eNOS, iNOS and COX-2 expression in the presence of Hcy, whereas GNE markedly induced eNOS, iNOS and COX-2 expression in the presence of Hcy. These findings indicated that GCE exerts 

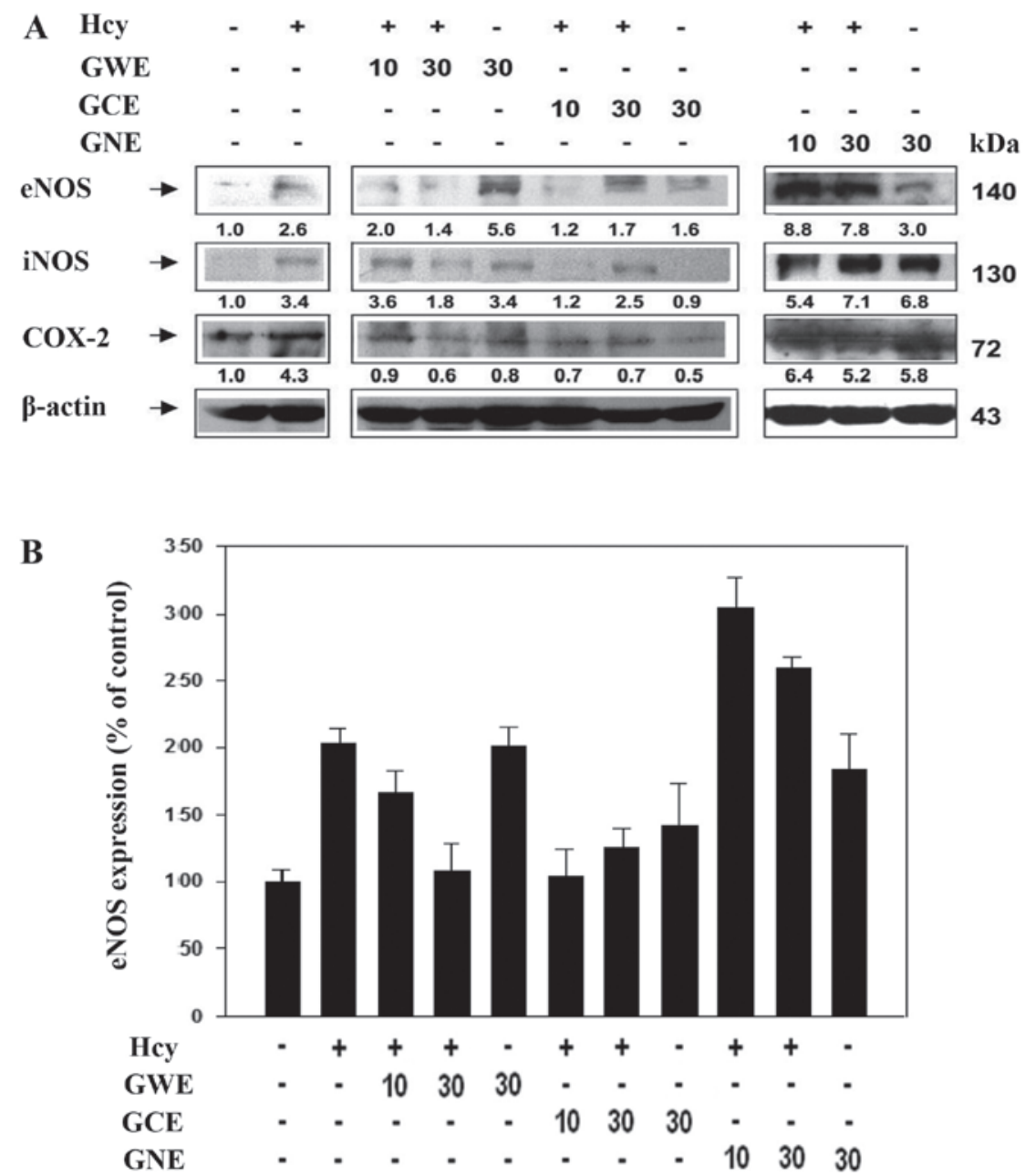

Figure 13. Vasoprotective effects of GCE were examined by western blot analysis. Porcine coronary artery rings were pretreated in the absence (control) or presence of 10 or $30 \mu \mathrm{g} / \mathrm{ml} \mathrm{GWE}, \mathrm{GCE}$ and GNE for $15 \mathrm{~min}$, and were then incubated with $100 \mu \mathrm{M}$ Hcy for $30 \mathrm{~min}$. Cells were harvested and (A) eNOS, iNOS and COX-2 expression were analyzed by western blot analysis. (B) eNOS activity was also analyzed. Values are expressed as the means \pm standard deviation of at least three independent experiments. COX-2, cyclooxygenase-2; eNOS, endothelial nitric oxide synthase; GWE, ginger water extract; GCE, ginger crude extract; GNE, ginger $n$-butanol extract; iNOS, inducible nitric oxide synthase.

stronger vasoprotective effects. In addition, eNOS expression was quantified from western blot analysis (Fig. 13B). These data suggested that GCE, not GWE or GNE, possesses a strong vasoprotective effect.

\section{Discussion}

Numerous phytochemicals used in traditional Chinese medicine have beneficial health effects on blood pressure and endothelial function (19,35). Ginger, which is a spice used to enhance the flavor of foods, has been used for centuries in the Taiwanese, Chinese, Indian, Arabic, Tibetan, Unani and Siddha systems of traditional medicine (7-9). It has previously been reported that ginger possesses various beneficial pharmacological effects, including hypoglycemic, insulinotropic and hypolipidemic activities, in humans and animals (13-16). Ginger, and its extracts, have also been reported to possess anticancer, analgesic and antioxidant pharmacological activities (11-13). The present study demonstrated that GCE exerts strong vasoprotective effects and exhibits free radical-scavenging abilities in porcine coronary arteries in vivo.

Ginger has been used to treat cardiovascular diseases for a long time, and it is known to exert diuretic and blood pressure-lowering functions $(7,9,10)$. In the present study, GCE relaxed porcine coronary arteries in a dose-dependent manner (Fig. 2). In rats, ginger has been reported to exhibit hypotensive, endothelium-dependent and -independent vasodilatory effects (36). Distinct receptors on the surface of the aorta and coronary arteries result in varying responses to stimulants. For example, epinephrine induces vasoconstriction of the aorta, but vasodilation of the coronary arteries (37). The present results indicated that GCE may relax KCl-induced contraction of endothelium-intact porcine coronary artery rings, whereas GCE only exerted a mild effect on relaxation of endothelium-denuded porcine coronary artery rings (Fig. 3). These data suggested that GCE may induce endothelium-dependent relaxation of porcine coronary arteries. NO is a major mediator of endothelium-dependent arterial relaxation.

Vasodilators, including NO, prostaglandin $\mathrm{I}_{2}$ and endothelium-derived hyperpolarizing factor, contribute to endothelium-dependent relaxation (38). The present results indicated that GCE-induced endothelium-dependent relaxation was markedly inhibited by ${ }_{\mathrm{L}}$-NNA, an endothelial NOS inhibitor (Fig. 4). NO activates SGC, which is responsible for the enzymatic conversion of GTP to cyclic GMP (cGMP). An 
increase in cGMP has been reported to mediate relaxation of coronary arteries. ODQ, which is a potent inhibitor of NO-activated sGC, inhibits NO-stimulated activity (39). In the present study, GCE-induced relaxation was significantly attenuated in the porcine coronary artery rings in response to pretreatment with ODQ (Fig. 5). These results indicated that the NO signaling pathway may be involved in GCE-induced relaxation of porcine coronary arteries. Arachidonic acid causes endothelium-dependent relaxation of coronary arteries (40). COX converts arachidonic acid into prostaglandin G2 (41). The present results indicated that GCE -induced relaxation was significantly attenuated in porcine coronary artery rings in response to pretreatment with indomethacin (Fig. 6). These data suggested that COX may be involved in GCE-induced relaxation of porcine coronary arteries.

Elevated Hcy levels in the blood (hyperhomocysteinemia) induce endothelial cell injury and are correlated with the occurrence of blood clots, which in turn may lead to atherogenesis. Hcy is a possible risk factor for coronary artery disease (42). Ilkhanizadeh et al (43) demonstrated that ginger extract may significantly reduce cardiac structural abnormalities in diabetic rats, and these effects were associated with improvements in serum apolipoprotein, leptin, cathepsin G and Hcy levels. The present results suggested that Hcy reduced relaxation, whereas GCE significantly prevented Hcy-induced endothelial dysfunction.

ROS are well-known mediators of vascular damage. $\mathrm{H}_{2} \mathrm{O}_{2}$ induces contraction in isolated canine basilar arteries (44). The present study revealed that GCE improved $\mathrm{H}_{2} \mathrm{O}_{2}$-induced endothelial cell injury, and possessed a stronger antioxidant ability to scavenge free radicals, compared with GNE and GWE. Dugasani et al (14) demonstrated that [6]-gingerol, [8]-gingerol, [10]-gingerol and [6]-shogaol exhibited substantial scavenging activities with half maximal inhibitory concentration $\left(\mathrm{IC}_{50}\right)$ values of $26.3,19.47,10.47$ and $8.05 \mu \mathrm{M}$ against DPPH radical, $\mathrm{IC}_{50}$ values of $4.05,2.5,1.68$ and $0.85 \mu \mathrm{M}$ against superoxide radical and $\mathrm{IC}_{50}$ values of $4.62,1.97,1.35$ and $0.72 \mu \mathrm{M}$ against hydroxyl radical, respectively. 6-Shogaol exhibited the most potent antioxidant and anti-inflammatory properties. In addition, elevated Hcy levels in the blood are associated with atherogenesis. It has been reported that Hcy increases the mRNA expression levels of eNOS and upregulates iNOS expression, thus resulting in COX-2 production, which eventually leads to the inflammatory response $(45,46)$. The present study examined the effects of ginger extracts on Hcy-induced endothelial cell damage and on the protein expression levels of eNOS, iNOS and COX-2. Hcy increased eNOS, iNOS and COX-2 expression, whereas GCE markedly reduced eNOS, iNOS and COX-2 expression in the presence of Hcy (Fig. 13). These results indicated that GCE may exert a strong vasoprotective effect.

In conclusion, the present study is the first, to the best of our knowledge, to demonstrate that GCE may induce relaxant and vasoprotective effects on porcine coronary arteries, and may possess free radical-scavenging activities. Therefore, GCE may be considered a potential cardioprotective factor in the context of human diseases.

\section{Competing interests}

The authors declare that they have no competing interests.

\section{References}

1. Ministry of Health and Welfare, Republic of China (Taiwan). https://www.mohw.gov.tw/cp-3425-33347-2.html, 2017.

2. Li H, Sun K, Zhao R, Hu J, Hao Z, Wang F, Lu Y, Liu F and Zhang Y: Inflammatory biomarkers of coronary heart disease. Front Biosci (Schol Ed) 10: 185-196, 2018.

3. Antonopoulos AS, Papanikolaou E, Vogiatzi G, Oikonomou E and Tousoulis D: Anti-inflammatory agents in peripheral arterial disease. Curr Opin Pharmacol 39: 1-8, 2017.

4. Salvo F, Bezin J, Bosco-Levy P, Letinier L, Blin P, Pariente A and Moore N: Pharmacological treatments of cardiovascular diseases: Evidence from real-life studies. Pharmacol Res 118: 43-52, 2017.

5. Brown AC: An overview of herb and dietary supplement efficacy, safety and government regulations in the United States with suggested improvements. Part 1 of 5 series. Food Chem Toxicol 107: 449-471, 2017.

6. Aggarwal M, Aggarwal B and Rao J: Integrative medicine for cardiovascular disease and prevention. Med Clin North Am 101: 895-923, 2017.

7. Shukla Y and Singh M: Cancer preventive properties of ginger: a brief review. Food Chem Toxicol 45: 683-690, 2007.

8. Baliga MS, Haniadka R, Pereira MM, Thilakchand KR, Rao S and Arora R: Radioprotective effects of Zingiber officinale Roscoe (ginger): past, present and future. Food Funct 3: 714-723, 2012.

9. Borrelli F, Capasso R, Aviello G, Pittler MH and Izzo AA: Effectiveness and safety of ginger in the treatment of pregnancy-induced nausea and vomiting. Obstet Gynecol 105: 849-856, 2005

10. Ghayur MN, Gilani AH, Afridi MB and Houghton PJ: Cardiovascular effects of ginger aqueous extract and its phenolic constituents are mediated through multiple pathways. Vascul Pharmacol 43: 234-241, 2005.

11. Connell DW and McLachla R: Natural pungent compounds: IV. Examination of the gingerols, shogaols, paradols and related compounds by thin-layer and gas chromatography. J Chromatogr A 67: 29-35, 1972.

12. Jolad SD, Lantz RC, Chen GJ, Bates RB and Timmermann BN: Commercially processed dry ginger (Zingiber officinale): composition and effects on LPS-stimulated $\mathrm{PGE}_{2}$ production. Phytochemistry 66: 1614-1635, 2005.

13. Macleod AJ and Pieris NM: Volatile aroma constituents of Sri Lankan ginger. Phytochemistry 23: 353-359, 1984.

14. Dugasani S, Pichika MR, Nadarajah VD, Balijepalli MK, Tandra S and Korlakunta JN: Comparative antioxidant and anti-inflammatory effects of [6]-gingerol, [8]-gingerol, [10]-gingerol and [6]-shogaol. J Ethnopharmacol 127: 515-520, 2010.

15. Mashhadi NS, Ghiasvand R, Askari G, Hariri M, Darvishi L and Mofid MR: Anti-oxidative and anti-inflammatory effects of ginger in health and physical activity: review of current evidence. Int J Prev Med 4 (Suppl 1): S36-S42, 2013.

16. Weng CJ, Chou CP, Ho CT and Yen GC: Molecular mechanism inhibiting human hepatocarcinoma cell invasion by 6 -shogaol and 6-gingerol. Mol Nutr Food Res 56: 1304-1314, 2012.

17. Shao Y, Yu Y, Li C, Yu J,Zong RR and Pei CG: Synergistic effect of quercetin and 6-gingerol treatment in streptozotocin induced type 2 diabetic rats and poloxamer P-407 induced hyperlipidemia. Rsc Adv 6: 12235-12242, 2016.

18. Ok S and Jeong WS: Optimization of extraction conditions for the 6-shogaol-rich extract from ginger (Zingiber officinale Roscoe). Prev Nutr Food Sci 17: 166-171, 2012.

19. Chang LC and Yu YL: Dietary components as epigenetic-regulating agents against cancer. Biomedicine (Taipei) 6: 2, 2016.

20. Gilani AH, Mandukhail SU, Iqbal J, Yasinzai M, Aziz N, Khan A and Najeeb-ur-Rehman: Antispasmodic and vasodilator activities of Morinda citrifolia root extract are mediated through blockade of voltage dependent calcium channels. BMC Complement Altern Med 10: 2, 2010.

21. Sakanashi M, Matsuzaki T and Aniya Y: Nitroglycerin relaxes coronary artery of the pig with no change in glutathione content or glutathione S-transferase activity. Br J Pharmacol 103: 1905-1908, 1991.

22. Sun B, Wang W and Salvaterra PM: Functional analysis and tissue-specific expression of Drosophila $\mathrm{Na}^{+}, \mathrm{K}^{+}$-ATPase subunits. J Neurochem 71: 142-151, 1998. 
23. Cohen RA, Plane F, Najibi S, Huk I, Malinski T and Garland CJ: Nitric oxide is the mediator of both endothelium-dependent relaxation and hyperpolarization of the rabbit carotid artery. Proc Natl Acad Sci USA 94: 4193-4198, 1997.

24. Lu CC, Yang SH, Hsia SM, Wu CH and Yen GC: Inhibitory effects of Phyllanthus emblica L. on hepatic steatosis and liver fibrosis in vitro. J Funct Foods 20: 20-30, 2016.

25. Lee CF, Yang JS, Tsai FJ, Chiang NN, Lu CC, Huang YS, Chen C and Chen FA: Kaempferol induces ATM/p53-mediated death receptor and mitochondrial apoptosis in human umbilical vein endothelial cells. Int J Oncol 48: 2007-2014, 2016.

26. Randriamboavonjy V, Busse R and Fleming I: 20-HETE-induced contraction of small coronary arteries depends on the activation of Rho-kinase. Hypertension 41: 801-806, 2003.

27. Randriamboavonjy V, Kiss L, Falck JR, Busse R and Fleming I: The synthesis of 20-HETE in small porcine coronary arteries antagonizes EDHF-mediated relaxation. Cardiovasc Res 65: 487-494, 2005.

28. Tomiyama $\mathrm{H}$ and Yamashina A: Beta-blockers in the management of hypertension and/or chronic kidney disease. Int J Hypertens 2014 919256, 2014

29. Gupta S and Wright HM: Nebivolol: a highly selective beta1-adrenergic receptor blocker that causes vasodilation by increasing nitric oxide. Cardiovasc Ther 26: 189-202, 2008.

30. Flagg TP, Enkvetchakul D, Koster JC and Nichols CG: Muscle $\mathrm{K}_{\text {ATP }}$ channels: recent insights to energy sensing and myoprotection. Physiol Rev 90: 799-829, 2010.

31. QuastU,Stephan D, BiegerS and Russ U: The impact of ATP-sensitive $\mathrm{K}^{+}$channel subtype selectivity of insulin secretagogues for the coronary vasculature and the myocardium. Diabetes 53 (Suppl 3): S156-S164, 2004

32. Drain P, Li L and Wang J: $\mathrm{K}_{\text {ATP }}$ channel inhibition by ATP requires distinct functional domains of the cytoplasmic $\mathrm{C}$ terminus of the pore-forming subunit. Proc Natl Acad Sci USA 95: 13953-13958, 1998

33. Valavanidis A, Vlahogianni T, Dassenakis M and Scoullos M: Molecular biomarkers of oxidative stress in aquatic organisms in relation to toxic environmental pollutants. Ecotoxicol Environ Saf 64: 178-189, 2006.

34. Wang F, Zhao S, Li F, Zhang B, Qu Y, Sun T, Luo T and Li D: Investigation of antioxidant interactions between Radix Astragal and Cimicifuga foetida and identification of synergistic antioxidant compounds. PLoS One 9: e87221, 2014.
35. Padma VV: An overview of targeted cancer therapy. Biomedicine (Taipei) 5: 19, 2015.

36. Tesfamariam B and Halpern W: Endothelium-dependent and endothelium-independent vasodilation in resistance arteries from hypertensive rats. Hypertension 11: 440-444, 1988.

37. Nabel EG, Ganz P, Gordon JB, Alexander RW and Selwyn AP: Dilation of normal and constriction of atherosclerotic coronary arteries caused by the cold pressor test. Circulation 77: 43-52, 1988.

38. Jiang J, Zheng JP, Li Y, Gan Z, Jiang Y, Huang D, Li H, Liu Z and Ke Y: Differential contribution of endothelium-derived relaxing factors to vascular reactivity in conduit and resistance arteries from normotensive and hypertensive rats. Clin Exp Hypertens 38: 393-398, 2016

39. Ghalayini IF: Nitric oxide-cyclic GMP pathway with some emphasis on cavernosal contractility. Int J Impot Res 16: 459-469, 2004.

40. Pratt PF, Rosolowsky M and Campbell WB: Mediators of arachidonic acid-induced relaxation of bovine coronary artery. Hypertension 28: 76-82, 1996.

41. Liu J, Seibold SA, Rieke CJ, Song I, Cukier RI and Smith WL: Prostaglandin endoperoxide $\mathrm{H}$ synthases: peroxidase hydroperoxide specificity and cyclooxygenase activation. J Biol Chem 282: 18233-18244, 2007.

42. Steed MM and Tyagi SC: Mechanisms of cardiovascular remodeling in hyperhomocysteinemia. Antioxid Redox Signal 15: 1927-1943, 2011.

43. Ilkhanizadeh B, Shirpoor A, Khadem Ansari MH, Nemati S and Rasmi Y: Protective Effects of ginger (Zingiber officinale) extract against diabetes-induced heart abnormality in rats. Diabetes Metab J 40: 46-53, 2016.

44. Mittal M, Siddiqui MR, Tran K, Reddy SP and Malik AB: Reactive oxygen species in inflammation and tissue injury. Antioxid Redox Signal 20: 1126-1167, 2014.

45. Förstermann $\mathrm{U}$ and $\mathrm{Li} \mathrm{H}$ : Therapeutic effect of enhancing endothelial nitric oxide synthase (eNOS) expression and preventing eNOS uncoupling. Br J Pharmacol 164: 213-223, 2011.

46. Matsumoto T, Goulopoulou S, Taguchi K, Tostes RC and Kobayashi T: Constrictor prostanoids and uridine adenosine tetraphosphate: vascular mediators and therapeutic targets in hypertension and diabetes. Br J Pharmacol 172: 3980-4001, 2015. 